\title{
An approach to diagnosing and managing diffuse lung disease presenting in the newborn period
}

\author{
M Coetzee, MB ChB, DCH (SA), FCPaed (SA), MMed (Paed), Cert Neonatology (SA), MPhil (Neonatology); \\ T W de Witt, MB ChB, MMed (Paeds), FCPaed (SA), DTE \\ Division of Neonatology, Department of Paediatrics and Child Health, Steve Biko Academic Hospital and Faculty of Health Sciences, University \\ of Pretoria, South Africa
}

Corresponding author: M Coetzee (mel.coetzee@up.ac.za)

\begin{abstract}
Although rare, diffuse lung disease is increasingly recognised as a cause of respiratory distress in newborns. However, many cases remain undiagnosed as not all clinicians are aware that these diseases may present during the newborn period. An increased index of suspicion is required in newborns not responding to conventional management, those with rapid deterioration of respiratory function and those with a family history of lung disorders. A structured diagnostic approach including radiography, genetic testing and lung histology should be followed, whereby a multidisciplinary team (neonatologist, pulmonologist, geneticist, radiologist and histopathologist) is involved. The mainstay of management is mostly supportive, and may include ventilation, infection prevention and control and nutritional support. Pharmacological therapy is based on anecdotal evidence. Although lung transplantation may be considered in some facilities, long-term post-transplant survival is poor.
\end{abstract}

S Afr J Child Health 2019;13(3):145-150. https://doi.org/10.7196/SAJCH.2019.v13.i3.1594

Although rare, diffuse lung disease (DLD) is increasingly recognised as a cause of respiratory distress and impaired gaseous exchange in the newborn period. ${ }^{[1]}$ However, the clinical presentation and imaging are non-specific in this heterogeneous group of diseases, and further testing is usually necessary to make a definitive diagnosis. ${ }^{[1,2]}$ DLD may occur in both premature and term newborns. Many clinicians may not consider DLD as a cause of respiratory distress in a newborn, and the American Thoracic Society has therefore developed a clinical practice guideline to prompt further investigation in some newborn infants. ${ }^{[3,4]}$ In all cases where DLD is suspected, a multidisciplinary approach (clinical, radiological and histological) is essential in making the correct diagnosis. ${ }^{[2]}$

This review article and case report demonstrates the diagnostic challenges and management dilemmas of a newborn with DLD.

Approval from the Research Ethics Committee, Faculty of Health Sciences of the University of Pretoria was obtained to prior to publication (ref. no. 389/2018). Additionally, consent to publish clinical details, photographs, radiographs and histology was obtained from both parents.

\section{Case report}

An early-term female infant was born to non-consanguineous parents at 37 weeks' gestation weighing $2840 \mathrm{~g}$ (appropriate for gestational age). She was born by caesarean section at a district hospital with no specialised neonatal services. Her Apgar scores were recorded as $9 / 10$ and $9 / 10$ at 1 and 5 minutes, respectively, and she did not require resuscitation at delivery. The parents have one other healthy child, a boy of school-going age.

She developed signs of respiratory distress (tachypnoea and recession) $\sim 24$ hours after birth, and was managed with supplemental nasal prong oxygen and antibiotics (penicillin G and gentamycin) for a presumed congenital pneumonia, although there were no risk factors for sepsis and her septic markers were low. Despite this treatment her distress worsened, and she was transferred to a tertiary institution on day 9 of life for invasive ventilation (Fig. 1). Her chest radiograph (Fig. 2) was typical of respiratory distress syndrome (as seen in premature newborns), and a congenital surfactant deficiency was considered. However, owing to prolonged hospital

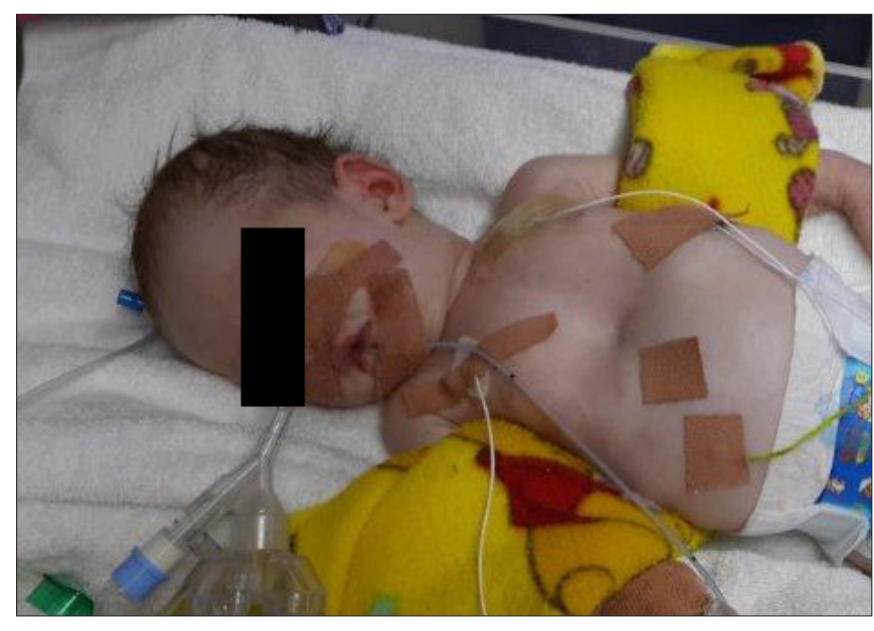

Fig. 1. Deep sternal recession while receiving positive pressure ventilation via an endotracheal tube (photograph supplied by parents).

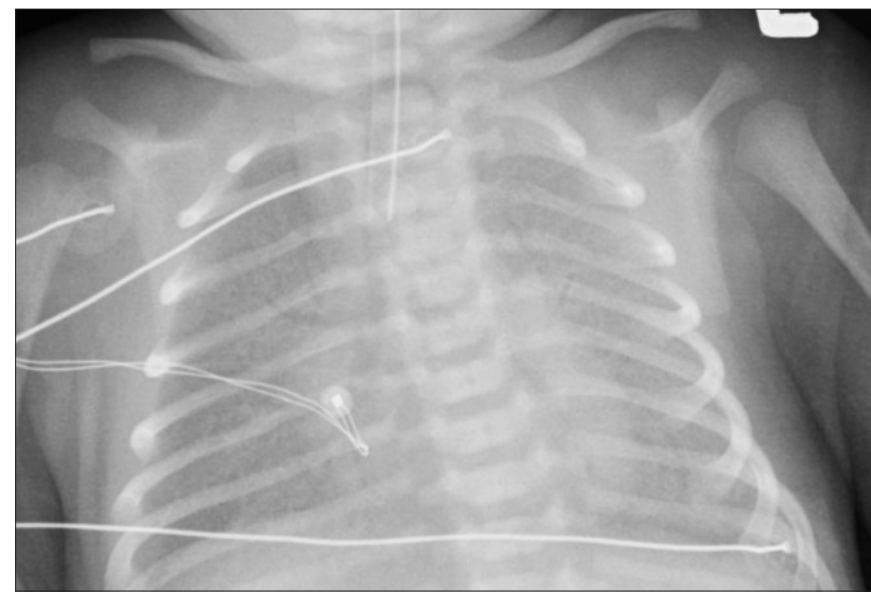

Fig. 2. Chest radiograph taken on day 9 of life, after intubation, showing diffuse ground-glass opacification. 
admission, a nosocomial pneumonia could not be excluded immediately, and meropenem was initiated, but stopped after 72 hours as her C-reactive protein (CRP) was $<1 \mathrm{mg} / \mathrm{L}$ and the blood culture was negative. Echocardiography revealed a structurally normal heart with trivial tricuspid regurgitation.

On the ninth day of invasive ventilation, the chest X-ray (CXR) showed perihilar consolidation with air bronchograms. The septic screen was repeated and oral erythromycin was initiated for a possible atypical pneumonia. The following day meropenem, vancomycin and fluconazole were added to her antimicrobial management. Her infective markers remained low (CRP $<10 \mathrm{mg} / \mathrm{L}$ ), and two additional peripheral blood cultures were negative. The vancomycin and fluconazole were stopped after 72 hours; however, the meropenem and erythromycin were continued for 7 days.

Two tracheal aspirates were taken to attempt to identify local pathogens in the lungs. The first aspirate cultured both Pseudomonas aeruginosa and Serratia marcescens, which were sensitive to Cefepime. The second aspirate cultured $P$. aeruginosa only. A bronchoscopy with bronchoalveolar lavage was considered, but the newborn was too unstable for this diagnostic intervention. Although her infective markers remained low, she received 7 days of Cefepime. The respiratory virus multiplex polymerase chain reaction was negative. A high vaginal swab, rectal swab and urine culture were performed on her mother to identify any possible causative pathogens, but none of these tests were helpful.

During her neonatal intensive care unit stay, her respiratory distress and respiratory function (oxygenation and ventilation) continued to deteriorate, resulting in changing from pressure assist-control conventional ventilation to high-frequency oscillation ventilation (HFOV), 11 days after admission (day 20 of life). At this stage it was agreed to give a dose of exogenous surfactant; however, there was still no improvement in her respiratory function. Although administration of systemic corticosteroids has been recommended only by anecdotal evidence, she was given a 7 -day trial of intravenous methylprednisolone (10 mg/kg daily), but again showed no clinical response. Due to the sideeffect profile of hydroxychloroquine, this immunosuppressant drug was not considered in the case of this newborn.

Although a diagnosis of congenital surfactant deficiency was strongly suspected, it could not be confirmed as genetic testing was not available. Additionally, a highresolution computed tomography (HRCT) scan of the chest was planned, but could not be performed as the infant was receiving HFOV. Although she had no neurological symptoms, thyroid function tests were performed to exclude a possible thyroid transcription factor-1 (TTF-1) mutation, which may cause congenital surfactant deficiency presenting in the newborn period. The results were normal.

Redirection of care was considered due to worsening respiratory failure, poor response to antimicrobials and systemic steroids and the recognised poor prognosis of surfactant dysfunction disorders presenting soon after birth. The family consented and the patient died peacefully on day 48 of life, soon after extubation. The diagnosis of ATP-binding cassette protein A3 (ABCA3) mutation was made based on immunohistochemistry and electron microscopy (Fig. 3 a - d) of the postmortem lung biopsy specimens.

\section{Aetiology of diffuse lung \\ disease}

An aetiological approach to classifying DLD, proposed by the chILD Research Co-operative, ${ }^{[1]}$ has been accepted by the American Thoracic Society, ${ }^{[2,3]}$ and divides them into two large groups: (i) those more prevalent in infancy; and (ii) those not specific to infancy. ${ }^{[3]}$ Recently, it was

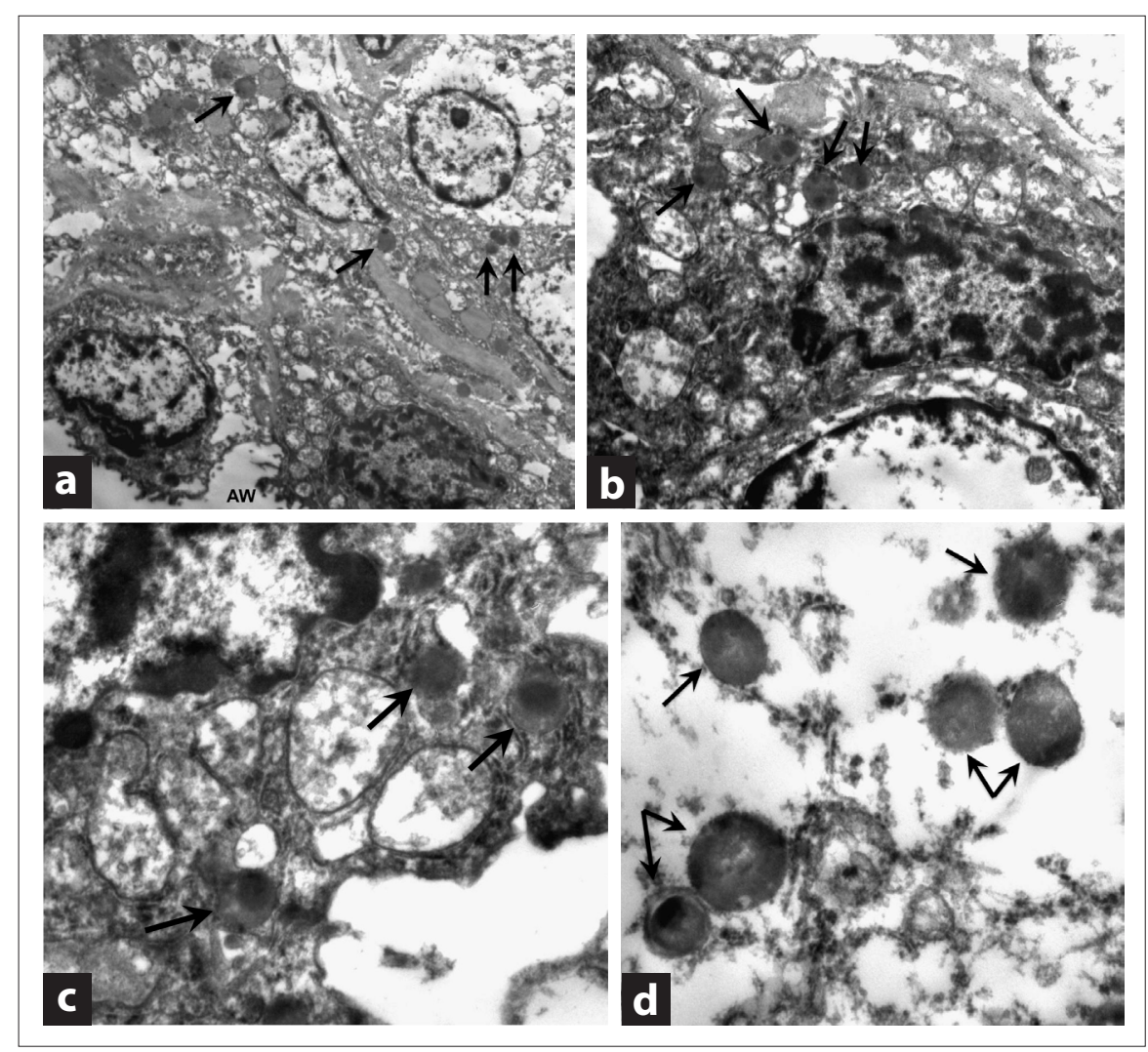

suggested that $\sim 68 \%$ of lung biopsies taken from infants $<1$ year of age were classified as 'disorders more prevalent in infancy,, and this discussion will therefore focus on this group of diseases. DLD that presents most commonly in the newborn includes diffuse developmental disorders, pulmonary interstitial glycogenosis and surfactant dysfunction mutations. ${ }^{[2,4]}$ Although the usual presentation of neuroendocrine cell hyperplasia of infancy (NEHI) is later in infancy, one case series describes six patients with NEHI that presented in the newborn period, ${ }^{[5]}$ and NEHI is therefore also included in the discussion. Similarly, surfactantprotein-C mutation (SFTPC) commonly presents later in infancy or childhood, but cases of newborn presentation have been described ${ }^{[6,7]}$ and it is therefore included. The classification, age at presentation and associated findings of DLD more common in infancy are listed in Table 1.

\section{Diagnostic approach}

Firstly, the clinician must identify those newborns who require further investigation. Common aetiologies for respiratory distress of the newborn should be excluded, such as pulmonary infection, ${ }^{[3]}$ recurrent aspiration ${ }^{[3]}$ (which may be related to tracheooesophageal fistula), ${ }^{[16]}$ congenital cardiac
Fig. $3 a$-d: Electron microscopy of alveolar type II cells demonstrating small lamellar bodies with eccentrically placed, tightly packed electron dense aggregates ('fried egg appearance'). Magnification of images: $a, \times 4000$;

$b, \times 9000 ; c, \times 18500 ; d, \times 26900$. 
Table 1. Prevalence, time of presentation and associated findings in DLD

\begin{tabular}{|c|c|c|c|}
\hline DLD & $\begin{array}{l}\text { Proportion of } \\
\text { total, } \%\end{array}$ & Age at presentation & Associated findings \\
\hline Diffuse developmental disorders & $11.1^{[1]}$ & & \\
\hline Acinar dysplasia & & Newborn $^{[2]}$ & - \\
\hline Congenital alveolar dysplasia & & $<2$ months $^{[2]}$ & - \\
\hline ACD-MPV & & Newborn $^{[2,3]}$ & $\begin{array}{l}\text { Significant pulmonary } \\
\text { hypertension, }{ }^{[3,8,9]} \text { cardiac, } \\
\text { gastrointestinal or genito- } \\
\text { urinary abnormalities }{ }^{[3,8-10]}\end{array}$ \\
\hline Congenital pulmonary lymphangiectasia ${ }^{[2]}$ & & Newborn $^{[2,3]}$ & $\begin{array}{l}\text { Noonan, Down, Turner and } \\
\text { Ehlers-Danlos syndromes, } \\
\text { chylothorax }^{[2]}\end{array}$ \\
\hline Growth abnormalities & $46.5^{[1]}$ & Newborn - 22 months ${ }^{[2]}$ & $\begin{array}{l}\text { Significant pulmonary } \\
\text { hypertension }^{[2]}\end{array}$ \\
\hline Pulmonary hypoplasia & & $\begin{array}{l}\text { Newborn (prenatal onset) - } 22 \\
\text { months }^{[2]}\end{array}$ & $\begin{array}{l}\text { Oligo-/anhydramnios, } \\
\text { congenital diaphragmatic } \\
\text { hernia, skeletal abnormalities, } \\
\text { neuromuscular } \\
\text { abnormalities }{ }^{[1,2]}\end{array}$ \\
\hline Chronic neonatal lung disease & & Newborn - 22 months ${ }^{[2]}$ & - \\
\hline $\begin{array}{l}\text { Structural pulmonary changes with chromosomal } \\
\text { abnormalities }\end{array}$ & & Newborn - 22 months ${ }^{[2]}$ & $\begin{array}{l}\sim 92 \% \text { associated congenital } \\
\text { heart disease }^{[1]}\end{array}$ \\
\hline Associated with congenital heart disease & & Newborn - 22 months ${ }^{[2]}$ & $\begin{array}{l}\text { Congenital heart disease with } \\
\text { limited pulmonary blood } \\
\text { supply }{ }^{[1]}\end{array}$ \\
\hline Undefined aetiology & $24.2 \%{ }^{[1]}$ & & \\
\hline Pulmonary interstitial glycogenosis & & $\begin{array}{l}\text { Newborn case series }{ }^{[3,11]} \\
<3 \text { months } \text { (not }>6 \text { months) }^{[2]}\end{array}$ & - \\
\hline NEHI/NEHI syndrome* & & $\begin{array}{l}\text { Newborn case series } ;^{[5]}<24 \\
\text { months }\end{array}$ & $\begin{array}{l}\text { May be precipitated by } \\
\text { lung infection; }{ }^{[2]} \text { male } \\
\text { predominance }^{[1]}\end{array}$ \\
\hline Surfactant dysfunction mutations & $18.2 \%^{[1]}$ & & \\
\hline SP-B & & Newborn $^{[2,3]}$ & - \\
\hline$A B C A 3$ & & Newborn; ${ }^{[3,8]}<3$ months ${ }^{[2]}$ & - \\
\hline SP-C & & Newborn; $;^{[6,7,12]} 2$ - 22 months ${ }^{[2]}$ & - \\
\hline TTF- $1^{[4]}$ & & Newborn; ${ }^{[3,13,14]}$ infancy $^{[15]}$ & $\begin{array}{l}\text { Hypothyroidism, neurological } \\
\text { abnormalities, }{ }^{[3,8] \dagger} \text { recurrent } \\
\text { pulmonary infections } s^{[4,15]}\end{array}$ \\
\hline \multicolumn{4}{|c|}{$\begin{array}{l}{ }^{*} \text { NEHI syndrome used when diagnosis based on characteristic clinical and high-resolution computed tomography findings, not lung biopsy. }{ }^{[8]} \\
{ }^{\dagger} \text { Neurological abnormalities in 'brain-thyroid-lung' syndrome include hypotonia (infants), cerebral dysgenesis, chorea (movement disorder) and developmental delay. }{ }^{[8]} \\
\text { DLD = diffuse lung disease; ACD-MPV = alveolar capillary dysplasia with misalignment of the pulmonary veins; NEHI = neuroendocrine cell hyperplasia of infancy; } \\
\text { SP-B = surfactant protein B; ABCA3 = ATP-binding cassette protein A3:SP-C = surfactant protein C } \text { TTF- } 1=\text { thyroid transcription factor-1. }\end{array}$} \\
\hline
\end{tabular}

disorders ${ }^{[3]}$ congenital diaphragmatic hernia ${ }^{[16]}$ lung hypoplasia and persistent pulmonary hypertension of the newborn. The American Thoracic Society clinical practice guideline requires at least three of the following four criteria to be met (in the absence of other known disorders) to prompt further investigation: $(i)$ the presence of respiratory symptoms (cough, difficult breathing); (ii) the presence of respiratory signs (tachypnoea, recession, added sounds on auscultation, respiratory failure); (iii) hypoxaemia; and (iv) the presence of diffuse abnormalities on CXR or CT. ${ }^{[3]}$ If a newborn or infant has DLD meeting these criteria, they are regarded as having 'childhood interstitial lung disease (chILD) syndrome. ${ }^{[3]}$ Fig. 4 shows a simplified approach to investigating these newborns.

\section{Radiology}

When a newborn presents with unexplained severe respiratory signs that are out of proportion to the presumed diagnosis, rapidly progressive disease or with a family history of chronic respiratory signs or interstitial lung disease, investigations should be done early to make a diagnosis. CXR is usually the first investigation to be done in the newborn presenting with respiratory distress, and although it may show diffuse abnormalities, it is not able to confirm the definitive diagnosis of DLD. HRCT of the chest is useful in identifying $\mathrm{NEHI},{ }^{[3,10]}$ preventing the need for more invasive testing (lung biopsy). ${ }^{[3,8,10]}$ However, in diseases such as surfactant dysfunction mutations, ${ }^{[4,10]}$ diffuse developmental disorders ${ }^{[9,10]}$ and pulmonary interstitial glycogenosis (PIG), ${ }^{[10,17]}$ HRCT is unable to make a definitive diagnosis and further testing is necessary. HRCT of the chest does not appear to be helpful in distinguishing between the growth abnormalities either. ${ }^{[4]}$ Table 2 illustrates the nonspecific radiological features of DLD more prevalent in infancy.

\section{Bronchoalveolar lavage}

Bronchoscopy with bronchoalveolar lavage is not very helpful in making a diagnosis in neonatal DLD. However it is useful in 


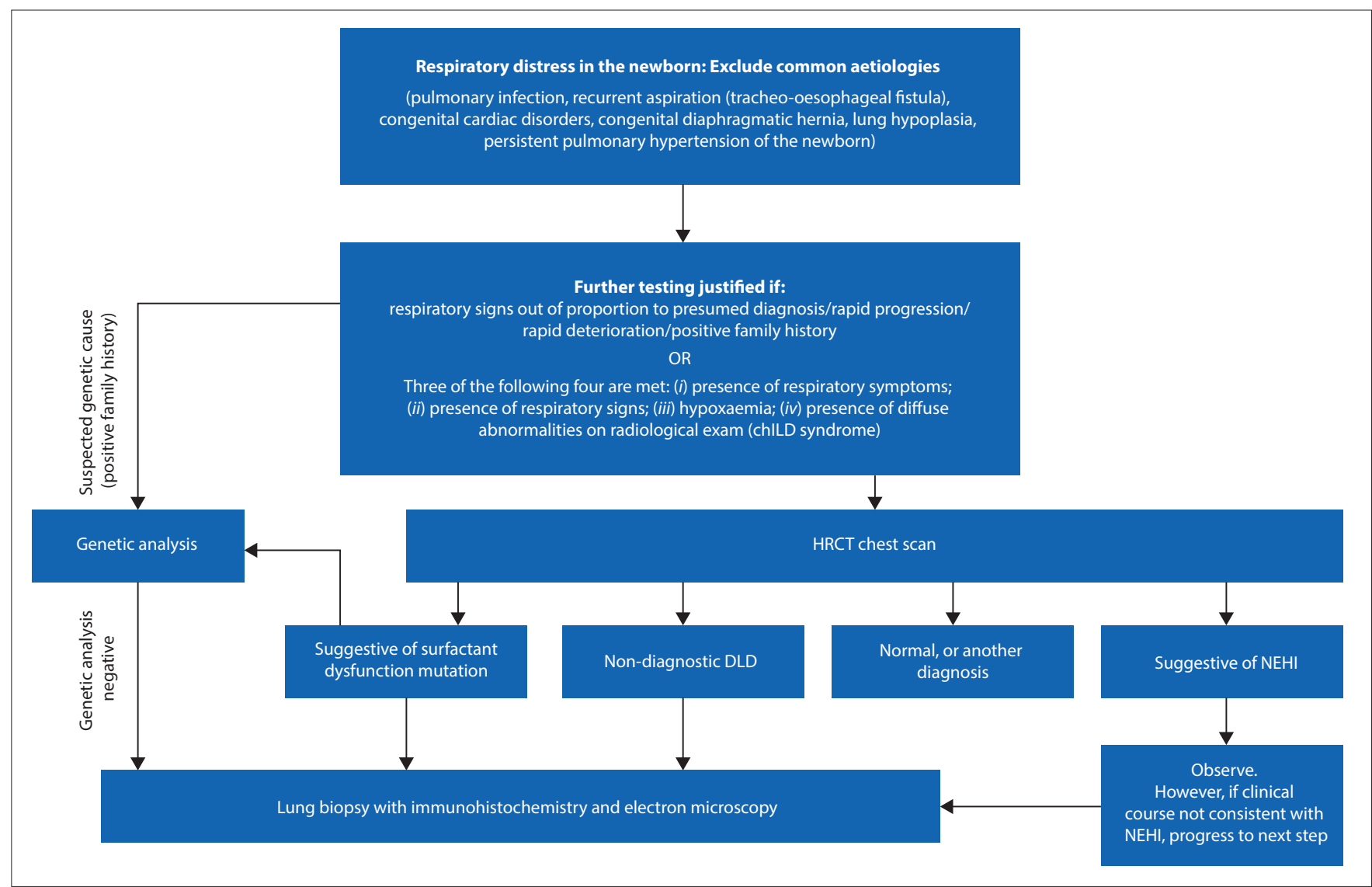

Fig. 4. Investigative approach to diffuse lung disease (DLD) presenting in the newborn (adapted from Kurland et al. $\left.{ }^{[3]}\right)$. $($ chILD = childhood interstitial lung disease; $H R C T=$ high-resolution computed tomography; NEHI = neuroendocrine cell hyperplasia of infancy.)

excluding infective causes, airway abnormalities and pulmonary haemorrhage..$^{[3,4]}$

\section{Genetic testing}

After a HRCT chest scan has been done, genetic studies are usually the next investigation if a gene mutation is suspected (Table 2) ${ }^{[3,4]}$ Congenital surfactant dysfunction disorders such as surfactant-protein-B mutation (SFTPB), ABCA3 mutation, and TTF-1 mutation (NKX2.1) can all be diagnosed by genetic testing. ${ }^{[3]}$ In these disorders, there is a positive family history in approximately one-third of cases. ${ }^{[1]}$ Alveolar capillary dysplasia with misalignment of the pulmonary veins (ACD-MPV) can also be diagnosed genetically (FOXF1 mutation) ${ }^{[3]}$ However, genetic results may take weeks to become available, and genetic diagnostic laboratories are not available in all countries, making a genetic diagnosis impossible in some patients.

\section{Lung biopsy}

Lung biopsy remains the gold standard in making the diagnosis for all cases of DLD where a genetic mutation is not suspected, the genetic analysis is negative or the HRCT of the chest is not diagnostic. ${ }^{[3]}$ In cases with rapid clinical deterioration, and where genetic testing is not available, an early lung biopsy is warranted, and paramount in order to make a specific diagnosis ${ }^{[3,4]}$ to guide management strategies, which are often based on the perceived prognosis of many of these diseases. ${ }^{[3]}$ Patients with suspected growth abnormalities should only be biopsied if the symptoms are disproportionate to the clinical circumstances ${ }^{[1,4]}$ Histology mostly reveals alveolar enlargement and simplification ${ }^{[2]}$ with 'patchy' PIG in $41-58 \%$ of cases. ${ }^{[1,8]}$ Although there are some overlapping features on light microscopy, the surfactant dysfunction mutations may be differentiated with the use of immunohistochemistry and electron microscopy. ${ }^{[13,14]}$ The quality of the histology is dependent upon adequate specimen preservation (formalin and glutaraldehyde) and processing, which should be done by an experienced professional. ${ }^{[2,3]}$ The histological features of DLD more prevalent in infancy are shown in Table 2.

\section{Management}

The mainstay of management is supportive, and may include ventilation (invasive and non-invasive), extracorporeal membrane oxygenation, nutritional support and infection control measures. ${ }^{[3,4]}$ Pharmacological treatment is based on anecdotal evidence, as there have been no controlled trials of therapeutic interventions. ${ }^{[3,4]}$ Immunosuppressive therapy in the form of pulse systemic methylprednisolone $(10-30 \mathrm{mg} / \mathrm{kg} / \text { day for } 3 \text { days })^{[4,19]}$ and steroid-sparing agents such as hydroxychloroquine $(5-7 \mathrm{mg} / \mathrm{kg} / \text { day })^{[4,19]}$ and azithromycin ${ }^{[4,19]}$ have been useful in isolated cases; however, owing to the lack of controlled trials, decisions about initiating this therapy should be made on a case-by-case basis. ${ }^{[3,4]}$ Disease severity, progression, ultimate prognosis and other comorbidities should all be taken into account when considering a trial of immunosuppressive therapy, as these drugs are not without side-effects. ${ }^{[3,4]}$ Pulmonary hypertension may be a prominent feature of some of these diseases and may require treatment with pulmonary vasodilatory therapy ${ }^{[9]}$ Lung transplantation is an option if end-stage lung disease is present; ${ }^{\left[{ }^{3]}\right.}$ however, the 5-year survival rate after lung transplantation is only $51 \%,{ }^{[3]}$ and lung transplantation is not available at all facilities. Supportive services, including social work, pastoral and psychological support should be offered to the family. ${ }^{[3]}$ Table 3 indicates which management strategy is most appropriate for each specific DLD. 
Table 2. Diagnostic investigations for DLD

\begin{tabular}{|c|c|}
\hline DLD & Diagnostic investigation \\
\hline \multicolumn{2}{|l|}{ Diffuse developmental disorders } \\
\hline Acinar dysplasia & $\begin{array}{l}\text { CXR: nonspecific hazy bilateral opacification; }{ }^{[10]} \text { histology: pseudoglandular or early canicular } \\
\text { stage of lung differentiation; airway limited to bronchial or bronchiolar structures }{ }^{[2]}\end{array}$ \\
\hline Congenital alveolar dysplasia & $\begin{array}{l}\text { CXR: nonspecific hazy bilateral opacification; }{ }^{[10]} \text { histology: late canalicular or early saccular } \\
\text { stage of lung differentiation }{ }^{[2]}\end{array}$ \\
\hline ACD-MPV & $\begin{array}{l}\text { CXR: normal, hazy or diffuse ground-glass opacification; }{ }^{[9]} \text { histology: interstitial thickening, } \\
\text { alveolar capillaries abnormally placed within the thickened septa, misalignment of pulmonary } \\
\text { veins, lymphangiectasia may be prominent: }{ }^{[2]} \text { may have alveolar growth arrest and pulmonary } \\
\text { interstitial glycogenosis; }{ }^{[2]} \text { genetics: } \mathrm{AR}^{[4]}(\text { FOXF1 } \sim 40 \%)^{[9]}\end{array}$ \\
\hline Congenital pulmonary lymphangiectasia $^{[2]}$ & $\begin{array}{l}\text { CXR: diffuse bilateral hazy opacification; }{ }^{[10]} \text { HRCT: thickening of septa and bronchovascular } \\
\text { bundles, patchy perihilar and subpleural ground-glass opacification, pleural thickening and } \\
\text { effusions; }{ }^{[10]} \text { histology: dilated lymphatic channels in bronchovascular bundle, inter-lobular } \\
\text { septa and pleura }{ }^{[2]}\end{array}$ \\
\hline
\end{tabular}

Growth abnormalities

Pulmonary hypoplasia

Chronic neonatal lung disease

HRCT: premature - hyperlucent areas, linear opacities, triangular subpleural opacities; term perilobular opacities and lobules of variable attenuation ${ }^{[10]}$

Structural pulmonary changes with chromosomal abnormalities HRCT: subpleural cysts (36\%), perilobular opacities and lobules of variable attenuation; ${ }^{[10]}$ histology: subpleural alveolar simplification; ${ }^{[2]}$ genetics: trisomy 21 most frequent ${ }^{[1,3,8]}$ HRCT: perilobular opacities and lobules of variable attenuation ${ }^{[10]}$

Associated with congenital heart disease

Undefined aetiology

Pulmonary interstitial glycogenosis

CXR: diffuse interstitial infiltrates, progressive hyperinflation; ${ }^{[8,10]}$ HRCT: ground-glass opacification (diffuse and 'patchy'), cystic lucencies, interlobular septal thickening; ${ }^{[17]}$ histology: diffuse expansion of interstitium with round mesenchymal cells with cytoplasmic clearing; ${ }^{[2]}$ may have alveolar growth arrest; ${ }^{[2,8,17]}$ electron microscopy: most reliable diagnostic method to demonstrate intracellular glycogen ${ }^{[2,4,8,11]}$

NEHI/NEHI syndrome*

HRCT: characteristic ground-glass opacification involving RML and lingula ('bat-wing deformity'), air trapping (mosaic pattern ${ }^{[2,8]}$ histology: usually normal-appearing lung biopsy on H\&E stain ${ }^{[2,8]}$ increased number of bombesin-immunopositive neuroendocrine cells in bronchioles; ${ }^{[2,4,8]}$ genetics: possible ${ }^{[8]} /$ heterozygous NKX2.1 mutation ${ }^{[18] \dagger}$

Surfactant dysfunction mutations $S P-B$ mutation

CXR and HRCT: diffuse, hazy, ground-glass opacification: $;{ }^{[4]}$ histology: granular proteinaceous deposits, anti-SP-B antibodies demonstrate absent SP-B expression in pneumatocytes; ${ }^{[2]}$ electron microscopy: deficient mature lamellar bodies; ${ }^{[2]}$ genetics: SFTPB mutation; $\mathrm{AR}^{[19,20]}$

$A B C A 3$ mutation CXR and HRCT: diffuse, hazy, ground-glass opacification; ${ }^{[4]}$ histology: 'glassy' intraalveolar proteinaceous deposits; ${ }^{[2]}$ electron microscopy: presence of distinctive electrondense bodies within small lamellar bodies ('fried egg' appearance) $;^{[2]}$ genetics: $A B C A 3$ mutation; $\mathrm{AR}^{[19,20]}$

SP-C mutation

CXR and HRCT: diffuse, hazy, ground-glass opacification; ${ }^{[4]}$ histology: interstitial inflammatory infiltrate, oedema and type II pneumatocyte hyperplasia ${ }^{[2]}$ electron microscopy: no characteristic changes; ${ }^{[2]}$ genetics: SFTPC mutation; $\mathrm{AD}^{[19,20]} /$ sporadic $50 \%{ }^{[8]}$

TTF-1 HRCT: bilateral ground-glass opacification ${ }^{[13,14]}$ and diffuse bronchial wall thickening; ${ }^{[13]}$ histology: may have alveolar growth arrest ${ }^{[2]}$ genetics: $\mathrm{AD} /$ sporadic (NKX2.1 gene deletion or mutation $)^{[2]}$

$\mathrm{DLD}=$ diffuse lung disease $\mathrm{CXR}=$ chest X-ray; $\mathrm{ACD}-\mathrm{MPV}=$ alveolar capillary dysplasia with misalignment of the pulmonary veins; $\mathrm{AR}=$ autosomal recessive; $\mathrm{HRCT}=$ high-resolution computed tomography; $\mathrm{NEHI}=$ neuroendocrine cell hyperplasia of infancy; RML = right middle lobe; H\&E = haematoxylin and eosin; $\mathrm{PAP}=$ pulmonary alveolar proteinosis; $\mathrm{DIP}=$ desquamative interstitial pneumonia; $\mathrm{SP}-\mathrm{B}=$ surfactant protein $\mathrm{B} ; A B C A 3=\mathrm{ATP}$-binding cassette protein $\mathrm{A} 3$; $\mathrm{SP}-\mathrm{C}=$ surfactant protein $\mathrm{C} ; \mathrm{AD}=$ autosomal dominant; TTF-1 = thyroid transcription factor- 1.

${ }^{*} \mathrm{NEHI}$ syndrome used when diagnosis based on characteristic clinical and HRCT findings, not lung biopsy. ${ }^{[8]}$

${ }^{4}$ Heterozygous NKX2.1 gene mutation identified in a family with NEHI (without thyroid or movement disorders). ${ }^{[18]}$ Speculated, however, that the NKX2.1 mutation is not the mechanism underlying NEHI, but rather that the gene(s) responsible for NEHI are regulated by TTF- $1 .{ }^{[18}$

\section{Prognosis}

DLD presenting in the newborn period usually has a poor prognosis, with $100 \%$ mortality reported for the SFTPB mutation, the $A B C A 3$ mutation (if respiratory signs are present early after birth) and the diffuse developmental disorders. ${ }^{[2]}$ Mortality rates are summarised in Table 3.

\section{Conclusion}

DLD should be considered in the differential diagnosis of a newborn with respiratory distress not responding to conventional management. A structured diagnostic approach should be followed whereby a multidisciplinary team (consisting of a neonatologist, pulmonologist, geneticist, radiologist and histopathologist) is 
Table 3. Management approach and mortality in DLD

\begin{tabular}{l}
\hline DLD category \\
\hline Diffuse developmental disorders \\
- Acinar dysplasia \\
- Congenital alveolar dysplasia \\
- ACD-MPV \\
- Congenital pulmonary lymphang \\
Growth abnormalities \\
- Pulmonary hypoplasia \\
- Chronic neonatal lung disease \\
- Associated with congenital hea \\
- Structural pulmonary changes \\
abnormalities \\
Undefined aetiology \\
- PIG \\
- NEHI/NEHI syndrome \\
Surfactant dysfunction mutations \\
- SP-B \\
- ABCA3 \\
- TTF-C
\end{tabular}

$\begin{array}{ll}\text { Management } & \text { Mortality } \\ \text { Supportive }^{[3,4] \star} & 100 \%^{[2,9]} \\ \text { Genetic counselling }^{[3]} & \\ \text { Pulmonary vasodilator therapy } & \\ \text { Lung transplantation }^{[3]} & \end{array}$

Supportive $e^{[3,4] *}$

Anti-failure therapy if cardiac abnormalities

Surgical cardiac interventions

Genetic counselling ${ }^{[3]}$

Supportive ${ }^{[3,4,8] \times}$

Systemic steroids controversial in PIG, ${ }^{[8,1]}$ and not recommended in $\mathrm{NEHI}^{[4,10]}$

Supportive $e^{[3,4] *}$

Systemic steroids ${ }^{[4,14,19]}$

Steroid-sparing agents $s^{[4,14,15,19] \dagger}$

Lung transplant (except for SP-C mutation $)^{[3,4]}$

Genetic counselling $^{[3]}$
Overall $34 \%^{[1,2]}$

Prematurity is an independent predictor of mortality ${ }^{[1]}$

Mortality increased with congenital heart disease ${ }^{[1]}$

$0 \%$ in pure diffuse PIG and NEHI ${ }^{[1,4]}$

Mortality variable if growth abnormalities and pulmonary hypertension present ${ }^{[4,11]}$ Morbidity is significant ${ }^{[18]}$ Overall $\sim 41 \%^{[1]}$ $100 \%$ for SP-B mutation ${ }^{[2]}$ $100 \%$ for $A B C A 3$ mutation if newborn presentation $^{[1]}$ $0 \%$ for SP-C mutation $^{[1]}$ Unknown in TTF-1

${ }^{*}$ Supportive management includes oxygen therapy, ventilation (non-invasive and invasive), extracorporeal membrane oxygenation, nutritional support and infection control measures.

'Steroid-sparing agents are hydroxychloroquine and azithromycin

$\mathrm{DLD}=$ diffuse lung disease; $\mathrm{ACD}-\mathrm{MPV}=$ alveolar capillary dysplasia with misalignment of the pulmonary veins; $\mathrm{NEHI}=$ neuroendocrine cell hyperplasia of infancy; $\mathrm{PIG}=$ pulmonary interstitial glycogenosis; SP-B = surfactant protein B; $A B C A 3=$ ATP-binding cassette protein A3; SP-C = surfactant protein C; TTF-1 = thyroid transcription factor-1.

involved. The mainstay of management is mostly supportive in the majority of cases where DLD is confirmed.

Acknowledgements. Mrs Esther Viljoen, Department of Anatomical Pathology, University of Pretoria (UP), for the electron microscopy images; Division of Paediatric Pulmonology, Department of Paediatrics and Child Health, Steve Biko Academic Hospital; Dr Engela Honey, Department of Biochemistry, Genetics and Microbiology, UP, for her contribution to this case.

Author contributions. MC drafted the case report, created the tables and described a simplified approach to DLD in newborns. TWdW reviewed the manuscript for scientific content. Both MC and TWdW approved the final article to be published.

Funding. None.

Conflicts of interest. None.

1. Deutsch GH, Young LR, Deterding RR, et al. Diffuse lung disease in young children. Application of a novel classification scheme. Am J Respir Crit Care Med 2007;176(11):1120-1128. https://doi.org/10.1164/rccm.200703-393OC

2. Armes JE, Misfud W, Ashworth M. Diffuse lung disease in infancy: A pattern-based algorithmic approach to histological diagnosis. J Clin Pathol 2015;68(2):100-110. https://doi.org/10.1136/jclinpath-2014-202685

3. Kurland G, Deterding RR, Hagood JS, et al. An official American Thoracic Society clinical practice guideline: Classification, evaluation and management of childhood interstitial lung disease in infancy. Am J Respir Crit Care Med 2013;188(3):376-394. https://doi.org/10.1164/rccm.201305-0923ST

4. Deterding RR. Infants and young children with children's interstitial lung disease. Pediatr Allergy Immunol Pulmonol 2010;23(1):25-31. https://doi.org/10.1089/ ped.2010.0011

5. Gomes VCC, Coelho-Silva MC, Maia Filho JH, et al. Diagnostic criteria and follow-up in neuroendocrine cell hyperplasia of infancy: A case series. J Bras Pneumol 2013;39(5):569-578. https://doi.org/10.1590/S180637132013000500007

6. Van Hoorn J, Brouwers A, Griese M, Kramer B. Successful weaning from mechanical ventilation in a patient with surfactant protein $\mathrm{C}$ deficiency presenting with severe neonatal respiratory distress. BMJ Case Rep 2014;2014(Jan). https:// doi.org/10.1136/bcr-2013-203053
7. Liptiz DR, Patel T, Deterding RR. Chronic ventilation in infants with surfactant protein C mutations: An alternative to lung transplantation. Am J Respir Crit Care Med 2015;191(11):1338-1340. https://doi.org/10.1164/rccm.201411 1955LE

8. Das S, Langston C, Fan LL. Interstitial lung disease in children. Curr Opin Pediatr 2011;23(3):325-331. https://doi.org/10.1097/MOP.0b013e3283464a37

9. Bishop NB, Stankiewicz P, Steinhorn RH. Alveolar capillary dysplasia. Am J Respir Crit Care Med 2011;184(2):172-179. https://doi.org/10.1164/ rccm.201010-1697CI

10. Guillerman RP. Imaging of childhood interstitial lung disease. Pediatr Allergy Immunol Pulmonol 2010;23(1):43-68. https://doi.org/10.1089/ped.2010.0010

11. Canakis A, Cutz E, Manson D, O’Brodovich H. Pulmonary interstitial glycogenosis. A new variant of neonatal interstitial lung disease. Am J Respir Crit Care Med 2002;165(11):1557-1565. https://doi.org/10.1164/rccm.2105139

12. Soraisham AS, Tierney AJ, Amin HJ. Neonatal respiratory failure associated with mutation in the surfactant protein C gene. J Perinatol 2006;26:67-70 https://doi.org/10.1038/sj.jp.7211417

13. Salerno T, Peca D, Menchini L, et al. Respiratory insufficiency in a newborn with congenital hypothyroidism due to a new mutation of TTF-1/NKX2.1 gene. Pediatr Pulmonol 2014;49(3):E42-44. https://doi.org/10.1002/ppul.22788

14. Jovien S, Borie R, Doummar D, Clement A, Nathan N. Respiratory distress, congenital hypothyroidism and hypotonia in a newborn. Respiration 2016;92(3):188-191. https://doi.org/10.1159/000449136

15. Safi KH, Bernat JA, Keegan CE, et al. Interstitial lung disease of infancy caused by a new NKX2-1 mutation. Clin Case Rep 2017;5(6):739-743. https://doi. org/10.1002/ccr3.901

16. Edwards MO, Kotecha SJ, Kotecha S. Respiratory distress of the term newborn infant. Paediatr Respir Rev 2013;14(1):29-37. https://doi.org/10.1016/j. prrv.2012.02.002

17. Weinman JP, White CR, Liptzin DR, et al. High-resolution CT findings or pulmonary interstitial glycogenosis. Pediatr Radiol 2018;48(8):1066-1072. https://doi.org/10.1007/s00247-018-4138-4

18. Young LR, Deutsch GH, Bokulic RE, Brody AS, Nogee LM. A mutation in TTF1/NKX2.1 is associated with familial neuroendocrine cell hyperplasia of infancy. Chest 2013;144(4):1199-1206. https://doi.org/10.1378/chest.13-0811

19. Somaschini M, Presi S, Ferrari M, Vergani B, Carrera P. Genetic surfactan dysfunction in newborn infants and children with acute and chronic lung disease. J Pediatr Neonat Individual Med 2017;6(1):e060134. https://doi. org/10.7363/060134

20. Wert SE, Whitsett JA, Nogee LM. Genetic disorders of surfactant dysfunction. Pediatr Dev Pathol 2009;12(4):253-274. https://doi.org/10.2350/09-01-0586.1

Accepted 12 December 2018. 